\title{
Schistosoma mansoni Infection and Its Related Morbidity among Adults Living in Selected Villages of Mara Region, North-Western Tanzania: A Cross-Sectional Exploratory Study
}

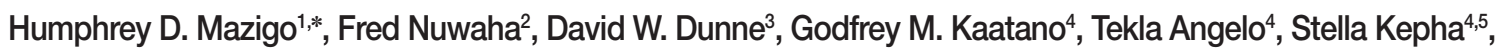 \\ Safari M. Kinung'hi' \\ ${ }^{1}$ Department of Medical Parasitology and Entomology, School of Medicine, Catholic University of Health and Allied Sciences, Mwanza, Tanzania; \\ ${ }^{2}$ Department of Disease Control and Environmental Health, School of Public Health, College of Health Sciences, Makerere University, Kampala, \\ Uganda; ${ }^{3}$ Department of Pathology, Division of Microbiology \& Parasitology, The University of, Tennis Court Road, Cambridge CB2 1QP, UK; \\ ${ }^{4}$ National Institute for Medical Research, Mwanza Research Centre, Mwanza, Tanzania; ${ }^{5}$ London School of Hygiene and Tropical Medicine, London, \\ United Kingdom
}

\begin{abstract}
Schistosoma mansoni is highly endemic in Tanzania and affects all age groups at different degrees. However, its control approach does not include adult individuals who are equally at risk and infected. To justify the inclusion of adult individuals in MDA programs in Tanzania, the present study focused on determining the prevalence of S. mansoni infection and its related morbidities among adult individuals. This was a cross sectional study conducted among 412 adult individuals aged 18-89 years living in selected villages of Rorya and Butiama districts located along the shoreline of the Lake Victoria. A pretested questionnaire was used to collect socio-demographic and socio-economic information of participants. Ultrasonographic examinations were conducted for all study participants using the Niamey protocol. A single stool sample was obtained from all study participants and examined for $S$. mansoni using the Kato-Katz technique. The study revealed a high prevalence of S. mansoni (56.3\%), and the majority of infected individuals had a light intensity of infection. Ultrasonographic findings revealed that $22.4 \%$ of adult individuals had periportal fibrosis (PPF) (grade C-F), with $18.4 \%$ having grade $C$ and $D$ and $4 \%$ having grade $E$ and $F$. Males had the highest prevalence of PPF $(31.7 \%$ vs $10.8 \%$, $P<0.001)$. Organomegaly was common with $28.5 \%$ and $29.6 \%$ having splenomegaly and hepatomegaly, respectively. $S$. mansoni infection and its related morbidities included PPF, hepatomegaly, and splenomegaly were common among adult individuals. To reduce the level of transmission of $S$. mansoni infection, planned mass drug administration campaigns should include adult individuals living in these villages.
\end{abstract}

Key words: Schistosoma mansoni, ultrasonography, organomegaly, adult, Mara, Tanzania

\section{INTRODUCTION}

Schistosomiasis caused by both Schistosoma mansoni and Schistosoma haematobium is highly endemic in Tanzania, and its prevalence varies from one epidemiological setting to another [1-3]. The available estimate indicates that almost 52\% of the estimated populations of 44 million Tanzanians are infected with schistosomiasis [1,2]. The disease is responsible for

- Received 23 April 2017, revised 23 August 2017, accepted 14 September 2017.

*Corresponding author (humphreymazigo@gmail.com)

(c) 2017, Korean Society for Parasitology and Tropical Medicine

This is an Open Access article distributed under the terms of the Creative Commons Attribution Non-Commercial License (http://creativecommons.org/licenses/by-nc/4.0) which permits unrestricted non-commercial use, distribution, and reproduction in any

medium, provided the original work is properly cited. causing significant morbidities, depending on the species; chronic $S$. mansoni infection is associated with hepatosplenic disease characterized by hepatic and splenic enlargements, progressive periportal fibrosis (PPF) which can lead to portal hypertension, and its related consequences [4-8].

Mass drug administration is most cost-effective when targeted at high risk groups, including school-aged children, preschool children, and women of child-bearing age who are most at risk of the negative health consequences as a result of helminth infection [9]. In Tanzania, control efforts against schistosomiasis mainly involve mass drug administration using praziquantel targeting mainly schoolchildren aged 5-14 years [9]. It is worthwhile to note that the outcome of chronic schistosomiasis, such as stunted growth, anemia [10], hepatic/ 
urinary bladder fibrosis $[6,7]$, and impaired cognitive developments [11,12], continues to have an effect throughout adulthood, although the age group may have lower intensity of infection. In addition, untreated adult population serves as a source of infection and reinfection to treated children and other members of the community $[13,14]$. The Tanzanian National Control against Neglected Tropical Diseases which include S. mansoni excludes adult individuals living in the same communities with the treated schoolchildren. To justify the inclusion of adults in MDA program in Tanzania, the present explorative study focused on determining the prevalence of intestinal schistosomiasis among adults aged $18-89$ years and describe S. mansoni morbidity in this area.

To our knowledge, by the time this study was conducted, Mara region had never received mass drug administration program against schistosomiasis, and little was known on the distribution of S. mansoni and its related morbidities among adult population in this region. A high prevalence and intensity of S. mansoni infection among schoolchildren had been previously described in the study setting [15]. However, data on the adult population was still missing and there was a need to understand the distribution of these infections in selected villages of the region and to generate data which would be beneficial for planning and implementation of the MDA programs.

\section{MATERIALS AND METHODS}

\section{Study area}

The study was conducted in Mara region, north-eastern Tanzania, the region lies between latitudes $1^{\circ} 0^{\prime}$ and $2^{\circ} 31^{\prime}$ South of the Equator and between longitudes $33^{\circ} 1^{\circ}$, and $35^{\circ} 15^{\prime}$ east of Greenwich meridian. The region has 6 districts namely Serengeti, Tarime, Bunda, Musoma, Butiama and Rorya. Specifically, the study involved 2 districts: Rorya and Butiama, which were conveniently selected because of their location on the Eastern shores of the Lake Victoria. The population of Rorya district is 265,241 of which $47.6 \%$ are males while the population of Butiama district is 241,732 of which $48.4 \%$ are males [16]. From the 2 districts, a total of 5 villages were conveniently selected from among villages based on their proximity to the lake shores. For Rorya district, 3 villages were selected based on their close proximity to the Lake Victoria shores, namely Sota, Busanga, and Kibuyi. For Butiama district 2 villages were selected namely Mwiringo and Bwai. The selection of the study villages was mainly based on their geographical

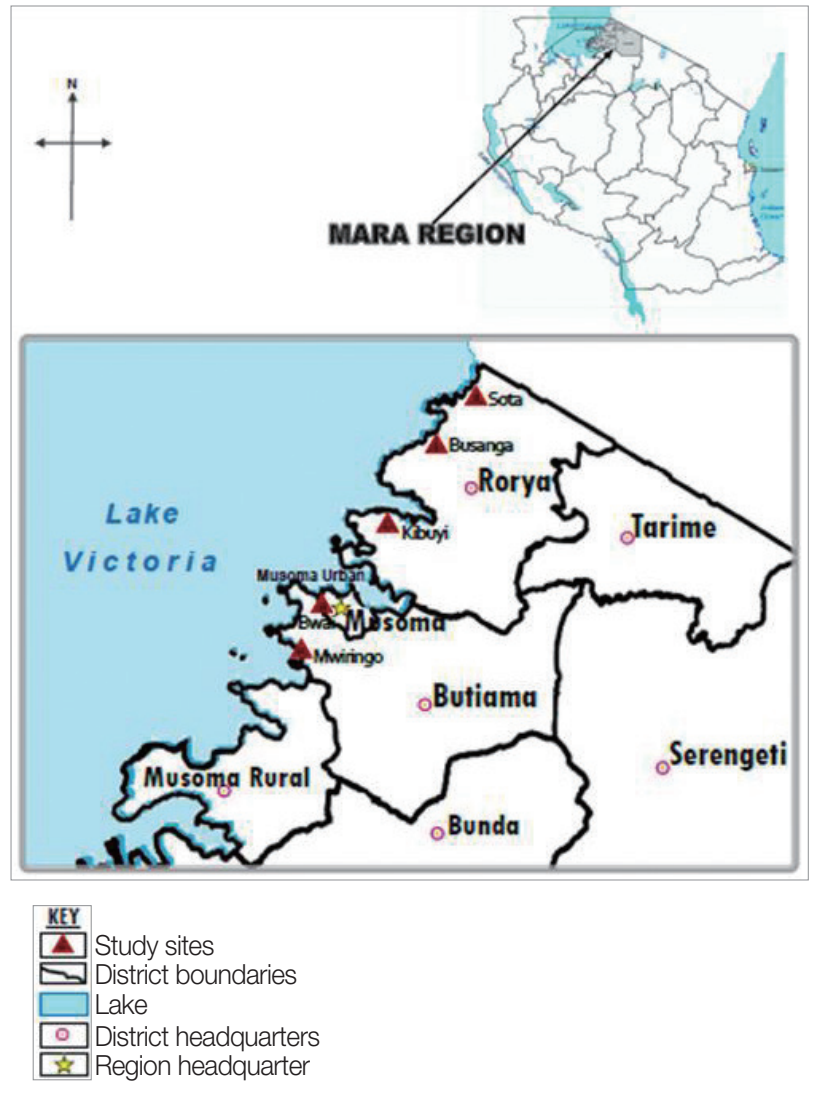

Fig. 1. Map of Tanzania showing Rorya and Butiama districts and the study villages in each district.

location close to the Lake Victoria shore, which present high risk for S. mansoni transmission [17]. Fig. 1 shows location of the study areas in north-western Tanzania.

\section{Study population, sample size, and inclusion criteria}

From each of the selected village, adults aged 18-89 years, both male and female, were randomly selected and included in the study. Study participants were selected if they were aged $\geq 18$ years, had lived in the study village for $\geq 2$ years, provided written informed consent, willing to submit stool and urine samples, accepting to undergo ultrasonographic examinations, and had no history of using anthelmintics (praziquantel and albendazole) in the past 6 months. Based on WHO recommendation [18], in order to evaluate for prevalence and intensity of helminth infections, a sample size of 100 adults individuals were required from each participating village. A total of 412 adults were included in the present study.

\section{Study design and sampling procedures}

This was a cross-sectional study that was conducted in Sep- 
tember 2013 and aimed at collecting parasitological, ultrasound (S. mansoni related morbidity), socio-demographic and socio-economic information of study participants. Two stage sampling procedures were used to select households and individual study participants. First, households were selected using simple random sampling method from a list of households obtained from village leaders and secondly, all adults aged 18 years and above from selected households were invited to participate in the study. At least 30 households were randomly selected from each village from which all adults aged 18 years and above were invited for interviews and parasitological and ultrasonographic examinations.

\section{Questionnaires}

A pre-tested Kiswahili translated questionnaire was used to collect socio-demographic and socio-economic activities of the study participants. The questionnaire was initially developed in English and then translated to Kiswahili and backtranslated by a different person who was blinded to the original questionnaire.

\section{Parasitological examinations for schistosomiasis and soil-transmitted helminth infections}

A single stool sample was obtained from all study participants, from which 2 Kato-Katz thick smears were prepared from a mixed stool samples (4 Kato slides for each study participants) using a template of $41.7 \mathrm{mg}$ (Vestergaard Frandsen, Lausanne, Switzerland) [19]. After $24 \mathrm{hr}$ of preparation, the Kato slides were examined for the presence of $S$. mansoni eggs at the National Institute for Medical Research Laboratory. Two experienced technicians examined the Kato-Katz smears. For quality assurance, a random sample of $10 \%$ of the negative and positive Kato-Katz thick smears were re-examined by a third technician.

\section{Anthropometric measurements}

Body height was measured in centimeters using a locally constructed stadiometer using a tape measure fixed on wooden board and weight was measured in kg using an electronic bathroom scale.

\section{Ultrasonographic examinations}

Ultrasonographic examinations were performed on each of the study participants using a portable ultrasound machine (Aloka SSD-500, Tokyo, Japan) based on the currently accepted Niamey protocol $[20,21]$. An experienced medical doctor trained on ultrasound and a Niamey protocol performed the examination using a portable ultrasound scanner equipped with a $3.5 \mathrm{MHz}$ curved transducer. The size of the liver (left and right lobes) and spleen was measured, and their height adjusted according to the reference population $[20,21]$. The portal hypertension (PH) score was calculated by combining the measurement of the diameter of the lumen of the portal vein (PV), and screening for the presence of ascites (ascites score) and porto-systemic collateral vessels (collateral score). For comparison of age independent analysis of organometric data, we used established height related reference data of the Senegalese population for the values of liver, spleen, and main portal vein $[20,21]$. Only qualitative methods using image pattern was used in assessing PPF.

Liver image grades were assessed as grade A, B, C, D, E, and $\mathrm{F}$ according to the guidelines $[20,21]$. The gallbladder wall thickness was measured when the gallbladder was well visualized. The thickness of the gall bladder was categorized as normal when it was less than $4 \mathrm{~mm}$, or increased when greater [21]. All measurements on ultrasonographic examinations were recorded in the ultrasound form.

\section{Treatment}

Based on the prevalence of $S$. mansoni observed in the study areas, all study participants were treated using praziquantel and albendazole. The treatment was performed under direct observation of a qualified nurse. After treatment, participants were requested to remain at the treatment site so that the study team can observe and manage any possible adverse effects.

\section{Ethical considerations}

Ethical clearance was granted by the Lake Zone Institutional Review Board (LZIRB), housed at the National Institute for Medical Research (NIMR), Mwanza Centre. The study received authorization from the regional and district administrative authorities of Mara region, Rorya and Butiama districts. Swahili translated informed consent forms were used to obtain participants' consent. For illiterate individuals, a thumb print was used to sign the consent forms after a clear description of the study objective was given.

\section{Data analysis}

Data entry was done at the National Institute for Medical Research, Mwanza Centre using a CSPro software and stored in the MYSQL database. Data analyses were performed using 
Stata version 13 (Stata Corp, College Station, Texas, USA) after data were checked for consistency and any errors cleaned. The prevalence of $S$. mansoni and soil-transmitted helminths with their 95\% confidence interval $(95 \% \mathrm{CI})$ were calculated using binomial regression taking into consideration of clustering by villages. Comparison of helminth infections by demographic factors was done using chi-square $\left(\chi^{2}\right)$ or Fisher's exact test. Mean eggs count of both $S$. mansoni and identified soil-transmitted helminths from the duplicate slides were obtained and multiplied by a factor of 24 to obtain the intensity of infection measured per gram of feaces (epg). Data were checked for normality and log transformed where necessary. Because of over dispersion of the helminths eggs, non log transformed arithmetic mean eggs with their 95\% CI are reported. Intensity of infection were classified as light, moderate and heavy based on the WHO guideline [9].

Ultrasonographic organomegaly was defined as left liver lobe, right liver lobe or spleen length exceeding 2 SD above the normal reference value where as right liver lobe shrinkage was defined as exceeding negative 2 SD below normal reference value. Main portal vein was also considered present if exceeding 2 SD above the normal reference value. Patterns A and $\mathrm{B}$ were considered to show no PPF while $\mathrm{C}, \mathrm{D}, \mathrm{E}$, and F were recorded as PPF.

\section{RESULTS}

\section{Demographic information of study participants}

A total of 412 adult individuals aged 18-89 years (median age 33 years; range 23-47.5 years) living in Busanga, Bwai, Kibuyi, Mwiringo and Sota villages participated in the present study (Table 1). Of these individuals, $54.4 \%$ were male and $45.5 \%$ were female. Majority of the study were married (65.1\%), living single $(27.9 \%)$ and $7 \%$ were widowed. In relation to education level, $20.2 \%$ were illiterate, $66.3 \%$ had attained primary school education and $13.6 \%$ had attained secondary or college education. The majority of the study participants were peasants (58.5\%), and $14.6 \%$ were involved in fishing activities. Other occupations mentioned by the study participants were small scale business, housewife, and secondary school students.

\section{Prevalence of S. mansoni infection in relation to demographic characteristics}

The overall prevalence of S. mansoni was 56.3\% (95\%; 43.674.7). The prevalence of $S$. mansoni infection did not differ by sex. The prevalence of $S$. mansoni varied significantly by village of residence $(P<0.001)$, with study participants living in Busanga (57.8\%), Kibuyi (66.3\%), and Bwai (73.2\%) having

Table 1. Prevalence of periportal fibrosis (PPF) and Schistosoma mansoni infection intensity and prevalence by age, sex, and village in Mara region, north-eastern Lake Victoria, and Tanzania

\begin{tabular}{|c|c|c|c|c|c|c|c|c|c|c|c|}
\hline & & & & & \multicolumn{7}{|c|}{ S. mansoni infection status } \\
\hline & \multicolumn{4}{|c|}{ Periportal fibrosis (PPF) } & \multicolumn{4}{|c|}{ Infection prevalence } & \multicolumn{3}{|c|}{$\begin{array}{c}\text { Intensity of infection } \\
\text { (geometrical mean no. of eggs } \\
\text { per gram of feces; EPG) }\end{array}$} \\
\hline & $\begin{array}{l}\text { No. of } \\
\text { exam }\end{array}$ & $\begin{array}{c}\text { Total no. } \\
(\%)\end{array}$ & M & $\mathrm{F}$ & $\begin{array}{l}\text { No. } \\
\text { exam }\end{array}$ & Total & M & $\mathrm{F}$ & All & M & $\mathrm{F}$ \\
\hline \multicolumn{12}{|c|}{ Age group (year) } \\
\hline $15-24$ & 47 & $3(6.4)$ & $2(7.7)$ & $1(4.8)$ & 120 & $75(62.5)$ & $45(65.2)$ & $30(58.8)$ & 202.1 & 177.9 & 234.8 \\
\hline $25-34$ & 108 & $24(22.2)$ & $17(25.8)$ & $7(16.7)$ & 98 & $54(55.1)$ & $31(55.2)$ & $23(54.8)$ & 92.8 & 116.4 & 61.4 \\
\hline $35-44$ & 78 & $24(30.8)$ & $21(51.2)$ & $3(8.1)$ & 69 & $36(52.2)$ & $13(41.9)$ & $23(60.5)$ & 96.2 & 55.0 & 129.8 \\
\hline $45-54$ & 53 & $14(26.4)$ & $12(41.7)$ & $4(13.8)$ & 61 & $32(52.5)$ & $17(58.6)$ & $15(46.9)$ & 154.0 & 242.5 & 73.9 \\
\hline $55-64$ & 45 & $9(20.0)$ & $6(26.1)$ & $3(13.6)$ & 26 & $14(53.9)$ & $9(60.0)$ & $5(45.6)$ & 120.9 & 153.6 & 76.4 \\
\hline $65+$ & 44 & $10(22.7)$ & $10(35.7)$ & $0(0.0)$ & 38 & $21(55.3)$ & $16(66.7)$ & $5(35.7)$ & 129.5 & 193.0 & 20.6 \\
\hline Total & 375 & 84 (22.4) & $66(31.7)$ & 18 (10.8) & 412 & 232 (56.3) & $131(58.5)$ & $101(53.7)$ & 139.4 & 354.1 & 122.2 \\
\hline \multicolumn{12}{|c|}{ Village name } \\
\hline Busanga & 63 & 25 (39.7) & 17 (45.9) & $8(30.8)$ & 64 & $37(57.8)$ & $26(68.4)$ & $11(42.3)$ & 132.6 & 159.8 & 92.8 \\
\hline Bwai & 92 & $13(14.1)$ & $10(24.4)$ & $3(5.8)$ & 97 & $71(73.1)$ & $26(61.9)$ & 45 (81.3) & 228.5 & 217.1 & 237.2 \\
\hline Kibuyi & 93 & 29 (31.2) & 27 (42.9) & $2(6.5)$ & 98 & 65 (66.3) & 48 (72.7) & $17(53.1)$ & 171.1 & 208.9 & 93.0 \\
\hline Mwiringo & 93 & $13(14.0)$ & $11(20.4)$ & $2(5.0)$ & 96 & $41(42.7)$ & $23(41.8)$ & $18(43.9)$ & 49.4 & 62.8 & 31.3 \\
\hline Sota & 34 & 4 (11.8) & $1(7.7)$ & 3 (13.6) & 57 & 18 (31.6) & 8 (34.8) & $10(29.4)$ & 98.8 & 88.2 & 96.0 \\
\hline Total & 375 & 84 (22.7) & $66(31.7)$ & 18 (10.8) & 412 & 232 (56.3) & $131(58.5)$ & $101(53.7)$ & 149.1 & 354.1 & 122.2 \\
\hline
\end{tabular}


the highest prevalence of infection. However, the prevalence of S. mansoni infection did not differ by level of education $(P=$ $0.16)$ and occupation $(P=0.31)$ of study participants.

\section{Intensities of $S$. mansoni infection}

The overall arithmetic mean of eggs per gram of feces (EPG) was 139.4 EPG (95\% CI: 103.0-175.9), with no mean difference between male and female participants $(P=0.39)$. Male individuals had a mean EPG of 153.9 (95\% CI; 107.2-200.5), and female individuals had a mean EPG of 122.2 (95\% CI; 64.6-179.9). The mean EPG varied significantly by village of residence $(P=0.013)$, with study participants living in Bwai (228.5 EPG, 95\% CI; 107.9-349.1) and Kibuyi (171.1 EPG, 95\% CI: 111.2-230.9) having the highest mean EPG. Based on the WHO categories of the intensity of infection, $75 \%$ of the infected individuals had light intensity, 15.3\% had moderate, and $9.7 \%$ had heavy intensity of infection.

\section{Prevalence of PPF}

Data for ultrasonographical examination were available for 384 individuals (Table 1). Of the $384,2.4 \%(n=9)$ individuals had other abnormality and were excluded in scoring and assessment of PPF using pattern image. Of the 375 total individuals examined by ultrasonography, 84 (22.4\%) had evidence of PPF (by Liver Image Pattern); 18.4\% had mild PPF (grade $\mathrm{C}$ and D) and $4.0 \%$ had severe PPF (grade $\mathrm{E}$ and F). Of the 15 individuals with severe PPF, 12 (3.2\%) had grade $\mathrm{E}$ and $3(0.8 \%)$ had grade F. The prevalence of PPF was higher in males (31.7\%) than females $(10.8 \% ; P=0.001)$. Prevalence of severe PPF was also remarkably higher in male (6.7\%) than female $(0.6 \% ; P=0.001)$. The prevalence of PPF increased with age to the highest peak at 35-44 years and afterward there was a decline and then almost remained constant throughout the later age of adulthood. In relation to village of residence, the prevalence of PPF was highest at Busanga (39.7\%) followed by Kibuyi (31.2\%) villages. The prevalence of PPF did not differ between individuals infected (56.3\%) or not infected (43.7\%) with $S$. mansoni infection $(P=0.17)$. In relation to intensities of $S$. mansoni infection, there was no significant change in proportion of adult individuals with PPF with an increasing in the categories of intensity of infection $(P$-trend $=0.483)$.

\section{Prevalence of hepatomegaly and splenomegaly}

Hepatosplenomegaly assessed as non-specific findings related to $S$. mansoni infection was also common in the study villages. Almost, $28.5 \%$ of the study participants examined had splenomegaly and $29.6 \%$ had left lobe hepatomegaly. The prevalence of right liver lobe hepatomegaly was $58.4 \%$ and portal hypertension was $19.2 \%$ (Table 2).

Of the 84 (22.4\%) individuals with PPF, 51 (60\%) had thickened gallbladder wall indicating evidence of involvement of PPF. All 51 cases of gallbladder wall thickening had PPF grade $\mathrm{D}$ and above. Nine had other non-specified pathological abnormalities of the liver not related to $S$. mansoni and majority 6 $(67.4 \%)$ had fatty liver, $2(22.2 \%)$ had hemangioma and $1(11.1 \%)$ had liver cirrhosis.

\section{DISCUSSION}

The findings of the present study corroborate findings of previous studies conducted among communities living along the Lake Victoria shore or on its islands that show high intestinal schistosomiasis among these communities $[1,22,23]$. The findings from the present study confirmed that adult popula-

Table 2. Prevalence of organomegaly and portal pressure by sex and village name in Mara region, north-eastern Lake Victoria, Tanzania

\begin{tabular}{|c|c|c|c|c|c|}
\hline \multirow[b]{2}{*}{ Variables/Category } & \multicolumn{3}{|c|}{ Liver size } & Spleen size & \multirow{2}{*}{$\begin{array}{c}\text { Portal pressure } \\
\text { PHT no. (\%) }\end{array}$} \\
\hline & No. examined & $\begin{array}{l}\text { Left liver lobe } \\
\text { enlargement no. (\%) }\end{array}$ & $\begin{array}{c}\text { Right lobe } \\
\text { enlargement no. (\%) }\end{array}$ & Splenomegaly no. (\%) & \\
\hline \multicolumn{6}{|l|}{ Sex } \\
\hline Male & 208 & 70 (33.7) & $114(54.8)$ & 67 (32.2) & 54 (26.0) \\
\hline Female & 167 & 41 (24.5) & 105 (62.9) & 40 (23.9) & $18(10.8)$ \\
\hline Total & 375 & 111 (29.6) & 219 (58.4) & 107 (28.5) & 72 (19.2) \\
\hline \multicolumn{6}{|l|}{ Village name } \\
\hline Busanga & 63 & 21 (33.3) & 35 (55.6) & $26(41.3)$ & $26(41.3)$ \\
\hline Bwai & 92 & 12 (13.0) & 60 (65.2) & 15 (16.3) & $6(6.5)$ \\
\hline Kibuyi & 93 & $40(43.0)$ & 58 (62.4) & $40(43.0)$ & 24 (25.8) \\
\hline Mwiringo & 93 & 28 (30.1) & 47 (50.5) & 16 (17.2) & $11(11.8)$ \\
\hline Sota & 34 & $10(29.4)$ & 19 (55.9) & 8 (23.5) & $5(14.7)$ \\
\hline Total & 375 & 111 (29.6) & 219 (58.4) & 107 (28.5) & 72 (19.2) \\
\hline
\end{tabular}


tion carries high prevalence of $S$. mansoni infection and its related organ morbidities [1,4-6]. This segment of the population may play a part as potential reservoirs and sources of infection to other members of the community.

The prevalence of $S$. mansoni observed in the present study among adult individuals was lower compared to reports from Ukerewe island within the Lake Victoria [4]. Similar to previous study among adult individuals in the same settings had reported a prevalence of $78 \%$ of S. mansoni infection [5]. However, the observed prevalence of $S$. mansoni was higher [17] than that observed in the mainland part of the Lake Victoria in Sangabuye, Igombe, Igalagala, and Kayenze villages [17]. The variations in prevalence of $S$. mansoni between epidemiological settings has been noted in part to be related to variation in transmission intensity between areas which is partly related to distribution of the intermediate host snails of the genus Biomphalaria [24]. In addition, human related water contact activities among adult population increase the chances for transmission of $S$. mansoni infection [4-7,22]. Communities living along the Lake Albert Uganda [25] have been repeatedly reported to have high prevalence of $S$. mansoni due to increased water contact behaviors. In relation to demographic factors of the study participants, we found high prevalence of $S$. mansoni infection among male individuals. This observation has been repeatedly reported in endemic areas and is partly explained by differences in water contact behaviors of the 2 sexes, which is mainly related to economic activities $[26,27]$.

Our findings noted a variation in prevalence of $S$. mansoni infection between villages. Similar findings were reported by previous studies in endemic areas, and a variation was observed even in nearby villages $[6,28]$. This mainly reflects the focal nature of transmission of $S$. mansoni and its related morbidities [29]. In relation to intensities of infection, the majority of the infected individuals had light to moderate and only few had heavy intensity of infection. Changes in water contact behavior with increased age and slow development of a partial immunity, partly may explain the low intensity of infection observed in the present study population [30-33]. In S. mansoni endemic areas, the age-pattern of prevalence and infection intensity shows that the age group of 6-15 years bears the highest intensity of infection compared to other age groups [34,35]. However, in areas with intense transmission with increased occupational exposure among adult aged individuals, this may result in maintenance of high intensities of infection in adulthood [31]. The observed high prevalence of S.mansoni in adult population has significant implications on the maintenance of transmission of the infection in endemic communities [14] and this segment of the population may serve as a source of infection to treated school children $[13,14]$. Thus, to control S. mansoni infection through preventive chemotherapy, it remains important to include the adult population.

Old endemic foci for $S$. mansoni infection are mainly characterized with broad spectrum of presentation of different types of organ morbidities among infected individuals with or without detectable S. mansoni eggs in stool samples [36]. The common morbidities detected in the present study population were PPF, hepatomegaly, splenomegaly and hepatosplenomegaly. These S. mansoni related morbidities have been repeatedly reported among adult population living along the shoreline of Lake Victoria [4-7]. However, their prevalence varies from one community to another, for instance, a recent study in Kome island, $42.2 \%$ of the adult individuals had PPF [7], $41 \%$ had PPF in Msozi village, Ukerewe island [4] and fishing village of the southern shore of the Lake Victoria, $14 \%$ of adult individual had PPF [6]. On the other hand, in the same setting, over $68 \%$ and $55 \%$ of the adult individuals had hepatomegaly and splenomegaly in Kome Island [7]. At Ukerewe island, $35 \%$ and $80 \%$ of the study participants had hepatomegaly and splenomegaly [4]. Geographical variation in prevalence of S. mansoni related morbidities in part could be explained by differences in prevalence and intensity of infection, transmission intensity of the parasites, length of exposure to the parasites [8,28], genetic background [37] and co-infection with other tropical diseases such as malaria [6]. Our study was not conducted without limitation; the sample size of 412 adult individuals may not be representative of the population living along the Lake shores in Mara region. However, comparing the findings observed in previous studies along the shore line of the Lake in Mwanza region [4-6] and neighborhood communities in Uganda [25], our findings gives a clear pictures of the prevalence and intensity of S.mansoni among adult individuals in the north-western region of the country. On the other hand, parasitological data reported here were based on single stool samples examined using Kato Katz techniques, which has poor sensitivity especially when only single stool sample is used for diagnosis, therefore its probable we may have underestimated the true prevalence of infection $S$. mansoni in the study population. We did not examine the presence of other endemic diseases such as malaria, which are important contributor of hepatomegaly and splenomegaly. 
In conclusion, S. mansoni infection and its related morbidities, such as PPF, hepatomegaly, splenomegaly, and hepatosplenomegaly are present in the adult population living in the selected villages. Our findings indicate that adult population may serve as potential reservoirs of $S$. mansoni infection and perpetuate the infection to treated schoolchildren. The observed hepatosplenomegaly morbidities may have significant implication on the health of the adult population. These findings call for the need to include the adult population in targeted mass drug administration program.

\section{ACKNOWLEDGMENTS}

This work was supported by Training Health Researchers into Vocational Excellence in East Africa (THRiVE) (grant no. 087540) funded by the Wellcome Trust. This was a part of the subsection of Prime grant. Its contents are solely the responsibility of the authors and do not necessarily represent the official views of the supporting offices. We acknowledge the technical support from the National Institute for Medical Research (NIMR) Mwanza Centre main laboratory staff. We thank all the study participants and the local government for allowing us to carry out this study.

\section{AUTHORS' CONTRIBUTIONS}

Humphrey Deogratias Mazigo, Godfrey Kaatano and Safari Methusela Kinung'hi designed the study and participated in data collection, analysis, and drafting of the first version of the manuscript. Teckla Angelo and Stella Kepha participated in data collection. David Wiliam Dunne and Fred Nuwaha critically reviewed the manuscript. All authors read and approved the final manuscript, contributed to the critical review, and made substantial contributions to its content.

\section{CONFLICT OF INTEREST}

The authors declare that they have no competing interests

\section{REFERENCES}

1. Mazigo HD, Nuwaha F, Kinung'hi SM, Morona D, Pinot de Moira A, Wilson S, Heukelbach J, Dunne DW. Epidemiology and control of human schistosomiasis in Tanzania. Parasit Vectors 2012; 5: 274.

2. Rollinson D, Knopp S, Levitz S, Stothard JR, Tchuem Tchuenté
LA, Garba A, Mohammed KA, Schur N, Person B, Colley DG, Utzinger J. Time to set the agenda for schistosomiasis elimination. Acta Trop 2013; 128: 423-440.

3. Brooker S, Kabatereine NB, Smith JL, Mupfasoni D, Mwanje MT, Ndayishimiye O, Lwambo NJ, Mbotha D, Karanja P, Mwandawiro C, Muchiri E, Clements AC, Bundy DA, Snow RW. An updated atlas of human helminth infections: the example of East Africa. Int. J Health Geogr 2009: 8: 42.

4. Kardorff R, Gabone RM, Mugashe C, Obiga D, Ramarokoto CE, Mahlert C, Spannbrucker N, Lang A, Günzler V, Gryseels B, Ehrich JH, Doehring E. Schistosoma mansoni-related morbidity on Ukerewe Island, Tanzania: clinical, ultrasonographical and biochemical parameters. Trop Med Int Health 1997; 2: 230-239.

5. Malenganisho WL Magnussen P, Friis H, Siza J, Kaatano G, Temu M, Vennervald BJ. Schistosoma mansoni morbidity among adults in two villages along Lake Victoria shores in Mwanza district, Tanzania. Trans R Soc Trop Med Hyg 2008; 102: 532-541.

6. Mazigo HD, Dunne DW, Morona D, Lutufyo TE, Kinung'hi SM, Kaatano G, Nuwaha F. Periportal fibrosis, liver and spleen sizes among S. mansoni mono or co-infected individuals with human immunodeficiency virus-1 in fishing villages along Lake Victoria shores, North-Western, Tanzania. Parasit Vectors 2015; 8: 260.

7. Kaatano GM, Min DY, Siza JE, Yong TS, Chai JY, Ko Y, Chang SY, Changalucha JM, Eom KS, Rim HJ. Schistosoma mansoni-related hepatosplenic morbidity in adult population on Kome Island, Sengerema district, Tanzania. Korean J Parasitol 2015; 53: 545551.

8. Booth M, Vennervald BJ, Kabatereine NB, Kazibwe F, Ouma JH, Kariuki CH, Muchiri E, Kadzo H, Ireri E, Kimani G, Mwatha JK, Dunne DW. Hepatosplenic morbidity in two neighbouring communities in Uganda with high levels of Schistosoma mansoni infection but very different durations of residence. Trans R Soc Trop Med Hyg 2004; 98: 125-136.

9. WHO Expert Committee. Prevention and control of schistosomiasis and soil-transmitted helminthiasis. World Health Organ Tech Rep Ser 2002; 912: 1-57.

10. World Health Organisation: Soil-transmitted helminthiases. Eliminating soil-transmitted helminthiases as a public health problem in children: progress report 2001-2010 and strategic plan 2011-2020. 2012; World Health Organ; Geneva 2012.

11. de Clercq D, Sacko M, Behnke J, Gilbert F, Vercruysse J. The relationship between Schistosoma haematobium infection and school performance and attendance in Bamako, Mali. Ann Trop Med Parasitol 1998; 92: 851-858.

12. Jukes MC, Nokes CA, Alcock KJ, Lambo JK, Kihamia C, Ngorosho N, Mbise A, Lorri W, Yona E, Mwanri L, Baddeley AD, Hall A, Bundy DA, Partnership for Child Development. Heavy schistosomiasis associated with poor short-term memory and slower reaction times in Tanzanian schoolchildren. Trop Med Int Health 2002; 7: 104-117.

13. Njenga SM, Mwandawiro CS, Muniu E, Mwanje MT, Haji FM, Bockarie MJ. Adult population as potential reservoir of NTD infections in rural villages of Kwale district, Coastal Kenya: impli- 
cations for preventive chemotherapy interventions policy. Parasit Vectors 2011; 4: 175.

14. Halwindi H, Magnussen P, Olsen A, Lisulo M. Potential contribution of adult populations to the maintenance of schistosomiasis and soil-transmitted helminth infections in the Siavonga and Mazabuka districts of Zambia. J Biosoc Sci 2016: 1-11.

15. Munisi DZ, Buza J, Mpolya EA, Kinung'hi SM: Intestinal schistosomiasis among primary schoolchildren in two on-shore communities in Rorya district, northwestern Tanzania: prevalence, intensity of infection and associated risk factors. J Parasitol Res 2016; 2016: 1859737.

16. National Bureau of Statistics. Tanzania national population and housing census, 2012. 2012.

17. Mazigo HD, Dunne DW, Wilson S, Kinung'hi SM, Pinot de Moira A, Jones FM, Morona D, Nuwaha F. Co-infection with Schistosoma mansoni and human immunodeficiency virus-1 (HIV-1) among residents of fishing villages of north-western Tanzania. Parasit Vectors 2014; 7: 587.

18. Montresor A, Cong DT, Sinuon M, Tsuyuoka R, Chanthavisouk C, Strandgaard H, Velayudhan R, Capuano CM, Le Anh T, Tee Dató AS. Large-scale preventive chemotherapy for the control of helminth infection in Western Pacific countries: six years later. PLoS Negl Trop Dis 2008; 2: e278.

19. Katz N, Chaves A, Pellegrino J. A simple device for quantitative stool thick-smear technique in Schistosomiasis mansoni. Rev Inst Med Trop São Paulo 1972; 14: 397-400.

20. Yazdanpanah Y, Thomas AK, Kardorff R, Talla I, Sow S, Niang M, Stelma FF, Decam C, Rogerie F, Gryseels B, Capron A, Doehring E. Organometric investigations of the spleen and liver by ultrasound in Schistosoma mansoni endemic and nonendemic villages in Senegal. Am J Trop Med Hyg 1997; 57: 245-249.

21. Richter J, Hatz C, Campagne G, Bergquist N, Jenkins JM: Ultrasound in schistosomiasis: a practical guide to the standard use of ultrasonography for assessment of schistosomiasis-related morbidity: Second international workshop, October 22-26 1996, Niamey, Niger. Tropical Diseases Research, World Health Organization, Geneva, 2000.

22. Mazigo HD, Waihenya R, Lwambo NJ, Mnyone LL, Mahande AM, Seni J, Zinga M, Kapesa A, Kweka EJ, Mshana SE, Heukelbach J, Mkoji GM. Co-infections with Plasmodium falciparum, Schistosoma mansoni and intestinal helminths among schoolchildren in endemic areas of northwestern Tanzania. Parasit Vectors 2010; 3: 44

23. Lwambo NJ, Siza JE, Brooker S, Bundy DA, Guyatt H. Patterns of concurrent hookworm infection and schistosomiasis in schoolchildren in Tanzania. Trans R Soc Trop Med Hyg 1999; 93: $497-$ 502.

24. Magendantz M. The biology of Biomphalaria choanomphala and B. sudanica in relation to their role in the transmission of Schistosoma mansoni in Lake Victoria at Mwanza, Tanzania. Bull World Health Organ 1972; 47: 331-341.
25. Kabatereine NB, Odongo-Aginya EI, Lakwo TL. Schistosoma mansoni along Lake Albert, Kibale District, western Uganda. East Afr Med J 1996; 73: 502-504.

26. Scott JT, Diakhaté M, Vereecken K, Fall A, Diop M, Ly A, De Clercq D, de Vlas SJ, Berkvens D, Kestens L, Gryseels B. Human water contacts patterns in Schistosoma mansoni epidemic foci in northern Senegal change according to age, sex and place of residence, but are not related to intensity of infection. Trop Med Int Health 2003; 8: 100-108.

27. Gazzinelli A, Bethony J, Fraga LA, LoVerde PT, Correa-Oliveira R, Kloos H. Exposure to Schistosoma mansoni infection in a rural area of Brazil. I. Water contact. Trop Med Int Health 2001; 6: 126-135.

28. Boisier P, Ramarokoto CE, Ravoniarimbinina P, Rabarijaona L, Ravaoalimalala VE. Geographic differences in hepatosplenic complications of schistosomiasis mansoni and explanatory factors of morbidity. Trop Med Int Health 2001; 6: 699-706.

29. Guyatt H, Gryseels B, Smith T, Tanner M. Assessing the public health importance of Schistosoma mansoni in different endemic areas: attributable fraction estimates as an approach. Am J Trop Med Hyg 1995; 53: 660-667.

30. Butler JR, Bingham J. Demography and human-dog relationships of the dog population in Zimbabwe communal lands. Vet Rec 2000; 147: 442-446.

31. Butterworth AE, Curry AJ, Dunne DW, Fulford AJ, Kimani G, Kariuki HC, Klumpp R, Koech D, Mbugua G, Ouma JH. Immunity and morbidity in human schistosomiasis mansoni. Trop Geogr Med 1994; 46: 197-208.

32. Gryseels B, Polderman AM. The morbidity of schistosomiasis mansoni in Maniema (Zaire). Trans R Soc Trop Med Hyg 1987; 81: 202-209.

33. Gryseels B, Polderman AM. Morbidity, due to schistosomiasis mansoni, and its control in Subsaharan Africa. Parasitol Today 1991; 7: 244-248.

34. Boisier P, Serieye J, Ravaoalimalala VE, Roux J, Esterre P. Ultrasonographical assessment of morbidity in schistosomiasis mansoni in Madagascar: a community-based study in a rural population. Trans R Soc Trop Med Hyg 1995; 89: 208-212.

35. Barakat R, Farghaly A, El Masry AG, El-Sayed MK, Hussein MH. The epidemiology of schistosomiasis in Egypt: patterns of Schistosoma mansoni infection and morbidity in Kafer El-Sheikh. Am J Trop Med Hyg 2000; 62 (suppl): 21-27.

36. Brooker S, Bethony J, Hotez PJ. Human hookworm infection in the 21st century. Adv Parasitol 2004; 58: 197-288.

37. Mohamed-Ali Q, Elwali NE, Abdelhameed AA, Mergani A, Rahoud S, Elagib KE, Saeed OK, Abel L, Magzoub MM, Dessein AJ. Susceptibility to periportal (Symmers) fibrosis in human Schistosoma mansoni infections: evidence that intensity and duration of infection, gender, and inherited factors are critical in disease progression. J Infect Dis 1999; 180: 1298-1306. 